Name: Anna Hamilton Jackman (A. H. Jackman)

Title: 3-D Cinema: Immersive Media Technology

Affiliation: PhD Candidate, Human Geography, University of Exeter

Address: University of Exeter, Geography, C252 Amory Building, Rennes Drive, Exeter, Devon, UK, EX4 4RJ

Email address: ahj203@ exeter.ac.uk

Conflict of interest: The author declares that they have no conflict of interest. 


\title{
3-D Cinema: Immersive Media Technology
}

\begin{abstract}
3-D cinema is a largely overlooked media within geographical critique. This omission is notable given both the sustained academic consideration afforded to other popular media, the medium's significant commercial and popular success, and its status as an 'affective' and captivating storytelling medium. With reference to film industry advertisements, the experiential dimensions of the 3-D cinematic encounter and its (popular) framing as an 'immersive' consumer experience are explored. In particular, the notion of 'immersion' is unpacked with reference to the medium's engineering and production techniques. In so doing, the intertwinement of the industrial desire for ever more 'immersive' and 'realistic' consumer experience is explored in relation to the engineering techniques exhibiting perceptual mimicry, or what could be termed 'mimetic engineering'. The association between 3-D cinema and 'tactile' images is then explored with reference to geographic literatures on 'haptics' and technologies of touch. A number of recent 'innovations' in these fields are drawn upon in order to complicate 3-D cinema's association with 'tactility'. In so doing, a technological shift towards the increasingly pervasive and sophisticated engagement of the wider multi-sensory palette is explored. Drawing upon recent media technology 'innovations', this persistent and relentless desire for ever more 'immersive' and perceptually-convincing media technology is explored in light of developing media geographies.
\end{abstract}

Keywords: 3-D Cinema, Media, Immersion, Technology, Haptics

\section{Introduction}

"Going to the Feelies this evening, Henry?" enquired the Assistant Predestinator. "I hear the new one at the Alhambra is first-rate. There's a love scene on a bearskin rug; they say it's marvellous. Every hair of the bear reproduced. The most amazing tactual effects" (Aldous Huxley 1984 in Paterson 2006. 691)

3-D cinema is a largely overlooked media within geographical critique. This paucity is notable given the sustained academic consideration afforded to other popular media, including, for example: newspaper cartoons (Dodds 1998, 2010a; Falah et al. 2006), videogames (Ash 2009, 2010a, 2010b, 2012; Ash and Gallacher 2011; Hughes 2010; Power 2007; Shaw 2010; Shaw and Sharp 2013; Shaw and Warf 2009; Stahl 2006), graphic novels (Holland 2012), comic books (Dittmer 2005, 2007), radio (Pinkerton and Dodds 2009), magazines (Sharp 2000), journalism (Pinkerton 2013), and film (Aitken and Dixon 2006; Carter and Dodds 2011; Carter and McCormack 2006; Dittmer 2011; Dittmer and Dodds 2013; Dodds 2010b; Lukinbeal and Zimmermann 2006, 2008; Pile 2011; Power and Crampton 2007; Shapiro 2009; Sharp 1998).

In making the case for a sustained consideration of 3-D cinema, this paper turns first to the medium's notable box office success and commercial popularity which show no signs of abating. As a medium premised and marketed precisely around its appeals to the non-representational, sensory experience, this paper then critically considers the 'affective' dimensions of this captivating storytelling medium. By exploring 3-D advertisements within the film industry, the paper then illustrates how the medium is framed in terms of its capacity to offer an 'immersive' consumer experience. This discussion of 'immersion' is then brought into conversation with the medium's underpinning engineering and production techniques. In so doing, the medium's engineering techniques are found to mimic human stereopsis processes in order to technologically construct a 'realistic' or depth-rich image. This process could be termed 'mimetic engineering'. A number of recent cinematographic developments, including 'higher frame rate' and 'screen $\mathrm{x}$ ', are then explored and are found to reflect the industrial goal of engineering ever more 'realistic' or perceptually-convincing cinematic experience.

In the paper's final substantive section, the coupling between (3-D) cinematic immersion and notions of 'tactility' are unpacked. In so doing, a dialogue is developed with geographic literatures exploring the technological realm of 'haptics', the development of technologies of touch. In working through a number of examples of each, it is found that both 3-D cinema and 'haptics' share a concern for the 'tactile' and employ 'mimetic engineering' in the quest for ever more 'immersive' and 'realistic' consumer experience. A number of recent 'innovations' in both fields, namely '4-D' / '5-D' cinema and augmented reality, are then drawn upon in order to complicate this association with the 'tactile'. In so doing, a notable shift from a focus on the 'tactile' to the industrial engagement of the wider multi-sensory palette is explored. Lastly, the case is made for the increasing import and applicability of such discussions across the wider technological media landscape.

\section{Why 3-D cinema?}


Many of us are familiar with 3-D cinema due to its sustained presence and domination of the contemporary box office. For example, in 2012 alone, 3-D cinema grossed \$1.8bn in US and Canadian box offices, accounting for 17\% of total box office revenues (Motion Picture Association of America 2013: 9). In the same period 3-D cinema grossed $£ 215.7 \mathrm{mn}$ in the UK and Republic of Ireland, accounting for $18 \%$ of total box office revenues (British Film Institute 2013: 14). Whilst the number of 3-D titles released in 2012 declined when compared with 2011, the 3-D format continues to draw in both substantial revenue and continued global investment in screen fittings, with such aforementioned cinematic bodies attributing this decline to an increasing discernment of when 3-D capabilities should be employed, rather than a consumption lull or consumer disinterest. Such sentiments are reflected by both the continued high revenues and the extensive media coverage and consumer "hype" around 3-D films. 'Avatar' (2009), for example, remains the highest grossing film ever to date, taking a record-breaking " $\$ 1$ bn $(£ 620 \mathrm{~m})$ at [global] cinema box offices" in its first three weekends alone (Guardian 2010: n.p.), whilst 'Gravity' (2013), another film popularly acknowledged as a show-case for refined 3-D cinematography, grossed $\$ 55.5 \mathrm{~m}$ in US and Canadian box offices on its opening weekend and $£ 6.2 \mathrm{~m}$ in its first four days at UK and Ireland box offices (of which around $90 \%$ of ticket sales were attributed to the 3-D format) (BBC News 2013: n.p.).

This picture of a commercially notable popular medium views 3-D cinema in its contemporary format only, however. It should be noted that 3-D cinema is not a new technology, rather one originating from a series of experiments with stereoscopic photography in the nineteenth century (see Crary 1992; Freeland 2012; Walters 2009; Zone 2007). The subsequent evolution and development of the technology was not a neat, linear and progressive one. Rather, a number of narratives of various iterations of the technology exist, due to its cyclical and periodic development, popularity and decline (see Elsaesser 2013; Gurevitch 2012; Hawkins 1953; Ross 2012; Walters 2009). Whilst not seeking to valorise 3-D cinema as a 'new' technology, this paper does wish to illustrate the value of exploring the medium in its contemporary format.

\section{Immersive 3-D cinema}

" $3 D$ definitely adds something to the experience. You get the depth of field you need to truly experience the movie and feel as though you're right there with Sandra" (Consumer Review, Gravity, IMDB 2013a)

"There are a bevy of 3D parlor tricks in the movie. They look great in 3D but are just silly. I am not gonna get into the stuff flying, floating, drifting into the third person camera. You know what they are and just what sort of cheap showmanship they are" (Consumer Review, Gravity, IMDB 2013b)

"So for 3-D film images that pop out of the screen, grab a seat and enjoy 3-D cinema like never before. Immerse yourself in an experience that cannot be replicated at home" (Reel Cinema advertisement 2014)

"When you watch a film in RealD 3D, you feel as though you've stepped inside it. Superb image quality - crisp, bright and ultra-realistic...the story's unfolding around you.... It's immersive: the film surrounds you" (Odeon Cinema advertisement 2014)

Despite this box office status 3-D cinema remains a largely overlooked popular medium within geographical scholarship. An exception to this relative paucity is Jason Dittmer's (2011) discussion of special and visual effects when considering 'American Exceptionalism' and the post 9/11 superhero film 'boom'. Dittmer's (2011) discussion of such cinematography is conducted through the lens of audience testimony. As Dittmer (2011) identifies, consumer vignettes and reviews akin to those opening this section can be evocative in pointing to the role of special and visual effects in audience appreciation and interpretation of film. Whilst the integration of such testimony certainly provides valuable methodological insight for (popular geopolitical) scholarship more widely, Dittmer (2011: 127) notably refers to the affective and "visceral thrills" left "outside [this] frame" of analysis. I therefore wish to build upon Dittmer's piece, further unpacking the experiential dimensions of 3-D cinematography specifically, an integral facet of the wider contemporary special and visual effects 'revolution'. Given the recent wave of discussions around the affective and experiential qualities of popular media (see Carter and McCormack 2010; Dittmer 2010, 2011; Hughes 2010, 2013; Pile 2011; Pinkerton and Dodds 2009), such a discussion of 3-D cinema, a medium premised precisely around appeals to the sensory, appears fitting. In critically considering the 'affective' dimensions of this captivating storytelling medium, this section reflects upon how the medium is framed, both by film industry rhetoric, consumer testimonies, and scholarly discourse, in terms of its capacity to offer an 'immersive' consumer experience. 
When sat in the cinema, glasses poised, with a 3-D film flickering ahead, it is not uncommon to see an audience member bring forth their hands to try and 'grasp' an image, or to "flinch...in response to objects thrown from the screen" (Ross 2012: 391). As will be expounded upon in the next section, 3-D cinematography strives to create such enchanting or mesmerising illusions via the technological creation of the impression of depth. This illusion of 'depth' is registered or 'felt' via our inbuilt 'proprioceptive' spatial sense. Proprioception refers to the bodily sense perceiving of "position, states and movement of the body" (Paterson 2007: ix), or the body's "recursive response" to "weight, dimension, gravity and movement in the world" (Crang 2002: 22; Sobchack 2004: 60). Through the creation of various depth planes, 3-D cinema thus stimulates perceptive responses via our 'proprioceptive' reflexes (Ash 2009; Paterson 2006, 2007). When the images 'pop out of the screen', as the opening advertisement proclaims, they spill and burst forth, appearing "more imma-nent" to the viewer (Shaw and Warf 2009: 1136). When coupled with advancements in surround and multi-channel sound (Prince 2012), the 3-D cinematic encounter can thus be understood as aiming to engage these 'somatic senses' as a unit acting in concert (Paterson 2007).

Across such descriptions 3-D cinema is presented as a medium that evokes and appeals to "kinesthetic sensation, haptic engagement, and an emphatic sense of wonder" (Bukatman 2003 in Dittmer 2011: 120). Such affective and sensory appeals function as an advertising hallmark for the film industry's 3-D cinema enterprise. Consider, for example, the advertisements opening this section. Such experiential qualities are showcased in the industry realm and across advertising vernacular with reference to a particular motif, that of 'immersion'. This can be exemplified more broadly by the standardised announcement acting a precursor to many 3-D films, stating: "Put on your 3-D glasses now. Prepare to be immersed". The Oxford English Dictionary (2014: n.p.) defines 'immersion' as a "deep mental involvement in something" (emphasis added). As the aforementioned discussions of 3-D cinema illustrate, however, the sensory and embodied dimensions of experience are central in this deployment of the term. When considered anew in terms of experiential (rather than solely 'mental') 'involvement', it is not difficult to see why 3-D cinema, a medium premised on sensory engagement and proprioceptive involvement, is often associated with 'immersion' in the industry and popular vernacular.

Whilst 'immersion' may constitute a notable component of 3-D cinematic experience, it must too be critically unpacked. For example, it is important to note that consumer experience of such popular media is of course not uniform, but plural, negotiated and contested (see Dittmer 2010; Glynn and Cupples 2014). Rather than "assuming a hypodermic model of media power, ascribing to "the media" the ability to inject their preferred messages into the minds of their audiences" (Dittmer 2010: 98, see also Barnett 2008: 193), we must appreciate 'immersion' as one of many possible experiences of 3-D cinema. For some, such as the consumer reviewer opening the section, 3-D cinematography adds to the experience. For others, however, it does not. For example, a recent MIT Technology Review (2010) details research conducted with viewers having just watched a 3-D film. The report notes that a number of viewers declared eyestrain and headaches. These strains were attributed to what is known as 'vergence-accommodation conflict' (MIT Technology Review 2010). This arises due to the slight difference in 'parallax conditions' when artificial 3-D images are viewed, and the resultant difference in the way the eyes must 'verge' or "rotate slightly inward or outward so that the projection of an image" remains "in the center of both retinas" (MIT Technology Review 2010: n.p.). Other discussions in this area mention additional forms of eyestrain such as 'binocular rivalry', 'diplopia' (aka 'double vision') and 'suppression' (Mendiburu 2012; Yang et al. 2012). Such research illustrates the importance of attending to the plurality of experiences of such technological media consumption, perception and reception. In addition, a number of commentators have noted that the very illusion of depth facilitating 3-D cinema's status as an 'immersive' medium is an "excessive" one, and that the "existence of 'flat' versions, along with promotional materials....that demonstrate content in 2D, makes it apparent that the story can be told without" 3-D cinematography (Ross 2013: 413). As such, the medium has (historically) been conceived of as a money-making enterprise or gimmick courtesy of the film industry (Hawkins 1953; Ross 2012, 2013). Whether conceived of as an artistic medium or an industrial gimmick, 3-D cinema shows no sign of abating and is thus worthy of sustained consideration.

Lastly, the notion of being 'immersed' is somewhat of a go-to word in our vernacular regarding popular media consumption more widely. Consider phrases such as 'getting lost' in a book, or being 'drawn into' a film. Whilst these instances and their connotations are notable, through the lens of 3-D cinema this paper aims to explore and unpack specifically the increasing technological sophistication of that advertised as ever more 'immersive' cinematic experience.

In briefly exploring the experiential aspects of 3-D cinema, this paper has sought to critically unpack and 'flesh out' the (framing of the) 'immersive' 3-D cinematic encounter. In so doing, it has sought to supplement textual explorations and conceptions of film as a narrative fiction with an appreciation of 3-D cinema's distinctive affective, experiential and 'immersive' appeals. The next section seeks to move from responding to the 
'rhetorical' framing and experiential dimensions of immersion within 3-D film to, instead, a critical reflection on the production processes underpinning the medium. In so doing, the intertwinement of this 'immersion' motif and discussions of 'realism' and perceptually-convincing engineering techniques will be explored.

\title{
Mimetic Engineering and naturalism
}

\author{
"Much of the effort of directors, designers, and draftspersons working in 3-D goes towards \\ naturalizing this type of technologically produced spatial vision, making it increasingly indiscernible" \\ (Elsaesser 2013: 221)
}

"We are born seeing in three dimensions. Most animals have two eyes, not one. There is a reason" (Film Director in Ross 2012: 381)

"The higher the frame rate, the more realistic the image, and even more so with $3 D$...The result is more like live performance...The viewer is in the movie, on the adventure." (Film Director in COW 2012: n.p)

Having fostered an appreciation of the experiential affective dimensions of 3-D cinema and filmic immersion, this paper wishes to bring into conversation the medium's underpinning engineering and production techniques. It proposes that 3-D cinematic production relies upon the 'reproduction' or mimicry of certain kinds of perception which it achieves via particular forms of what could be termed 'mimetic engineering'. Drawing upon discussions of 'biomimicry', described as "reverse-engineer[ing] animal life to develop technologies and tactics that solve social and environmental problems" (Johnson 2010: 177; see also Johnson 2011; Kovac 2014), this paper considers 'mimetic engineering' as that which 'reverse-engineers' or mimics human sensory faculties. Paterson (2006: 700) employs a similar conception of sensory mimicry in technological development via what he terms 'retro-engineering' in a discussion of 'haptic' engineering (see below). This differential consideration of mimesis is not to overlook the important scholarly dialogue around the established representational 'reel' / 'real' binary, with its own politics of the mimetic (see Crampton and Power 2007; Dixon and Grimes 2004; Lukinbeal 2004; Lukinbeal and Zimmermann 2006; Marks 2000), but rather to consider mimesis through a different analytic frame. By bringing into conversation experiential discussions of 'immersive' 3-D cinema with the engineering that underpins the medium I hope to illustrate how increasing demands for techno-realistic experience, both in the case of 3-D cinema and across the media technology landscape more widely, intersect with and rely upon biological, embodied and naturalistic knowledges.

Having moved on from the days of red-green anaglyph glasses, the current popular format of 3-D cinema functions via a method known as 'polarisation'. Consumers wear polarised stereoscopic glasses which pick up separate projections from two synchronised projectors, each operating from a different perspective (Ross 2012). Crucially there is a horizontal disparity, known as a 'parallax', between these perspectives. 3-D cinematography utilises negative, positive and zero parallax techniques in order to manipulate the resultant 'stereopsis' (3-D rendition) (Ross 2012). For example, negative parallax techniques or 'emergence effects' are utilised to visually foreground an image (Klinger 2013; Reeve and Flock 2010; Ross 2013), at once creating the illusion of an 'ultra-realistic' depth-rich scene, and "destabilising" the audience's "traditional" relationship with the screen (Odeon 2014; Ross 2013: 407). This 'parallax' is also what accounts for the appearance of blurriness or 'double vision' if the polarised glasses are removed. If the projection streams and glasses are seen in conjunction however, the harmonious impression of a third dimension is created (Lipton 2010). This technological creation and manipulation of dimensionality is the cornerstone and signature of the medium's popularity and success.

If we consider such mechanics anew, clear design similarities to human binocular vision emerge. Binocular vision refers to the 'stereopsis' we experience due to the distance between our eyes ('interocular distance') causing an image to be seen from two slightly different angles, which when combined in the brain form a threedimensional image (Howard and Rogers 1995; Reeve and Flock 2010). Understood through the lens of 'mimetic engineering', we see clear parallels between our sensibilities and the design and engineering of this mechanised process. Through this process of 'mimetic engineering' 3-D cinema thus seeks to (re)create or mimic our 'natural' experience. In so doing, it produces an experience distinguishable from the photo-realistic, instead achieving a more depth-rich topography, exuding a "sense of 'tele-presence': an extended spatiality through the screen" (Ash et al 2009: 467).

This mimetically engineered "spatial verisimilitude" (Elsaesser 2013: 239) continues to be refined through various technological ventures, leaps and forays. Consider, for example, recent cinematographic advancements in Higher Frame Rate 3D (HFR 3D). Trialled in the two 3-D hit films thus far released in 'The Hobbit' trilogy 
(2012; 2013), HFR 3D is a production technique showcasing, in its latest iteration, 48 frames per second (fps) rather than the standard cinematic 24fps. This essentially means that the camera shutter is closed less, and more frames and motion data are produced in between (Tech Radar 2012: n.p.). By increasing the number of frames shown per second, this technique boasts the reduction of both "motion blur", "the strobing of fast-moving images" and "flickering" in order that scene changes may appear more seamless and movement thus more 'realistic' (Tested 2014: n.p.; PopSci 2013: n.p.). The higher number of frames thus aims to decrease such sideeffects or 'unnatural' interruptions to the image stream. A number of film directors have labelled such developments as rendering 3-D film more "immersive" (Gizmodo 2012: n.p.). As in the section's opening quotations, here we see an emergent coupling between the advertisement and discussion of 3-D cinematography as increasingly 'immersive' and its underpinning engineering striving for a more 'realistic' or 'natural' consumer experience whereby "the human eye [sees] a much smoother movement" (Tech Radar 2012: n.p.) in order for the medium to become ever more "perceptually convincing" (Prince 2012: 183).

Interestingly, this coupling is one that extends across the wider cinematic landscape. Consider for example the recent unveiling of a new cinematic experience dubbed 'Screen $X^{\prime}$ in South Korea. Described as presenting the viewer with a wider "270-degree field of vision that creates an immersive experience without the need to wear 3-D glasses" (Independent 2013: n.p.), the medium 'constructs' depth via the placing of three large screens to produce a "hyper-wide panorama", aiming to simulate and stimulate "peripheral vision" (The Verge 2013; DVICE 2013). Such an experience can be seen as a technological extension of the established IMAX cinema format that has a 146-degree view (DVICE 2013: n.p.). Whilst the first half-hour film to be shown utilising 'Screen $X$ ' technology has only recently been premiered, such developments illustrate (3-D) cinema's continuously refined desire for the creation of an immersive and perceptually-mimicking encounter. Such developments have also been mirrored and domesticated with recent technological advancements in 3-D televisions, specifically those that now boast 'curved' screens such as LG's recent range bringing you "an eyepopping world of immersive detail...at home" (Currys 2014: n.p.). This section has thus aimed to explore a dialogue between 3-D cinema as an 'immersive' medium and one designed and engineered around the (re)creation or approximation of 'natural' human visual perception.

\section{3-D cinema and beyond}

“The New Dimension of Entertainment. 3-D: Touch the film” (Odeon Cinema advertisement 2014)

"[D-Box seating] enables the moviegoer to live the action that is taking place onscreen, providing an unmatched, realistic, immersive experience" (D-Box advertisement 2014)

"With intuitive touch control and exciting features for the whole family, the Microsoft Surface...is the ideal tablet" (Tablet advertisement, PC World 2014)

"Embedded S Pen: Real Pen-like feeling for natural writing experience” (Tablet advertisement, Samsung 2014)

"Touching is knowing" (Tablet advertisement, Currys 2013)

\section{Tactility}

In this section the coupling of 3-D cinematic immersion with notions of 'tactility' is unpacked. The paper then explores the utility of consulting 'haptics' literatures in order to develop and make the case for a consideration of 'mimetic engineering' across the wider media technology landscape. In so doing, it explores developmental similarities in recent innovations in both fields, seeking to complicate a focus upon 'tactility'.

As has been established, whether via an audience 'grasp' or involuntary flinch at created illusions, 3-D cinema is often said to exemplify a kind of 'tangibility' or 'tactility' (Loew 2013; Ross 2012, 2013). As the opening advertisement from cinema chain 'The Odeon' demonstrates, this 'tactility' is an integral component of 3-D cinema's industrial immersive status. Scholarly discussions around 2-D cinema commonly also refer to the 'tactile' appeal of cinema, evoking and foregrounding the sensory and more-than-visual dimensions of cinematic experience. Accounts such as Marks' (2000: 162) discussion of "haptic perception" and "haptic visuality" propose that "the eyes themselves function like organs of touch". Marks (2000: 163) notably discusses the distinction between "optical perception" and "haptic perception", with former "privileging the representational power of the image" and the latter instead "privilege[ing] the material presence of the image". 
Such approaches are said to valuably move towards "considering the ways cinema appeals to the whole body" (Marks 2000: 163). Similarly, Sobchack's (2004: 67) elaboration of the 'cinesthetic subject' denotes both "the complexity and richness of the...bodily experience of cinema, and....also.... [the] ways in which the cinema uses our dominant senses of vision and hearing to speak comprehensively to our other senses". In discussing the film 'The Piano', Sobchack (2004: 62) wonderfully illustrates the sensuous resonances and reverberations of film, evoking a notable sense of tactility in the 2-D format. Ross (2013), however, has reconsidered such engagements with regard to 3-D cinema specifically. In particular, Ross (2013: 408) draws upon Bruno's (2002) discussion of the 'field screen'. The 'field screen' refers to a "habitable geographic space" in which a tactile and haptic apprehension of space occurs (Bruno 2002: 250), comprised of a "tactile eye and visual touch" (Bruno 2002: 253). In her reworking, Ross (2013: 408) considers the 3-D field screen as "constituted by... an embodied viewer who is encouraged to be cognisant of sensory perception that extends beyond optical observation", developing discussions of "haptic affects" and a "hyperhaptic visuality" (Ross 2012: 383, 384). Clearly there is an established association between (3-D) cinema and notions of 'tactility'. In order to further unpack this coupling, I turn now to geographic literature exploring the technological field of 'haptics' which directly engages with the engineering of 'tactility'. Whilst 3-D cinema and the field of 'haptics' engage differently with the tactile, both utilise forms of 'mimetic engineering' in order to create ever more 'immersive' and 'realistic' consumer experiences. 'Haptics' is also a commonplace component of many devices across the wider media technology landscape, and is thus a valuable resource to draw upon and demonstrate the wider applicability of these discussions.

'Haptics', stemming from the Greek "haptethai", can be defined as "of, pertaining to, or relating to the sense of touch or tactile sensations" (Paterson 2007: 4). In the technology sphere this translates to the development of interfaces and 'technologies of touch' (Paterson 2006). A familiar product of 'haptics' is the touch-screen found in many media devices, including smartphones and tablet computers. This manifestation of 'haptics' is becoming increasingly pervasive with smartphone and tablet device ownership at $51 \%$ of all adults in the UK (Ofcom 2013: 3), and similarly 56\% of adults in the U.S own smartphones (Pew Research Center 2013a: 1) and $34 \%$ own tablets (Pew Research Center 2013b: 2). Like 3-D cinema, 'haptics' is also underpinned by the engineering goals of 'realism', 'intuition' and perceptual-mimicry, but in this case via gestures and touch specifically (Dourish 2001 in Kitchin and Dodge 2011: 218). In addition, akin to 3-D cinema, 'haptics' has experienced many 'innovations' and technological iterations. Paterson $(2006,2007)$ provides an invaluable history of a series of such iterations. In so doing he works through the example of the PHANToM ${ }^{\mathrm{TM}}$, a robotic 'desktop' 'haptic' interface famously facilitating the first "virtual handshake". Seeking to build upon such scholarship, this paper considers recent 'haptics' innovations functioning instead in the domestic and popular spheres.

A notable innovation leading to the mainstream uptake of a now pervasive component of 'haptics', 'multitouch', occurred in 2007 when 'Apple' launched the 'iPhone'. 'Multi-touch' refers to a device's ability to "recognize and respond to touch inputs at multiple locations simultaneously" (AIS 2013: 2). Apple popularised a form of 'multi-touch' with the 'pinch-to-zoom' capability whereby users are able to expand and contract content "by sliding [their] thumb and forefinger apart and pinching them together to restore the original size" (PC Mag 2013: n.p.). This capability has since become synonymous with Apple's wider product-lines, as well as being integrated across the Android and technological device landscape more widely. 'Multi-touch' has been continually refined in a bid to make it ever more sensorily responsive or perceptually 'natural'. Consider, for example, the recent surge of increasingly sophisticated handwriting capabilities in the tablet computing sphere. As the opening advertisements illustrate, the value of the 'touch' capabilities feeling 'natural' or 'intuitive' is commonly emphasised. Fierce competition around the development of an ever more "precise stylus" or the "best-note-taking" ability and "writing experience" (Digital Trends 2013: n.p.) illustrates, as in the case of 3-D cinema, both the role of mimetic engineering and the industry rhetoric surrounding the value placed on the emulation of 'realistic' and 'natural' sensory experience.

A similar pervasive, popular and commercially notable manifestation of 'haptics' can be seen through the case of 'force-feedback' in the videogames sector. Within this context 'force feedback' refers to a tactile sensation, vibration, or reverberation sent back through the controller when particular gaming scenarios arise - for example low character health or upon experiencing gunfire (Hughes 2010; Paterson 2006, 2007). Such capabilities are increasingly marketed as key components in the wider "immersive" gaming experience. For example, the widely anticipated and reported Playstation 4 'Dualshock' controller boasts both a 'sensitive' touch panel and sophisticated force-feedback capacities with "enhanced vibration” (Playstation 2014: n.p.), each labelled as integral to the wider "immersive" gaming experience. Additional features also include motion-sensing gyroscopes and a speaker, marketed as facilitating a "more personal and intimate" gameplay experience (Youtube 2013). Such features reflect precisely the industry focus upon "exploiting and manipulating...sensory 
experience" (Shaw and Warf 2009: 1332), and the centrality of 'tactility' or 'hapticality' in this endeavour. Through advertising discourse such as "even the subtlest movements can be turned into precise controls" (Playstation 2014: n.p.) the goal of a tactile-inflected perceptual mimicry or 'mimetic engineering' is again industrially foregrounded.

\section{Recent innovations: beyond tactility}

Thus far it is evident that 3-D cinema and 'haptic' technologies share both a concern with the 'tactile' dimensions of popular media experience and the employment of 'mimetic engineering' in order to (re)create forms of sensory realism. They too are underpinned by similar industrial rhetoric and semantics surrounding 'immersion' and 'natural' or 'realistic' experience. Given a media landscape in which advancements of both 3$\mathrm{D}$ cinema and broader 'haptic' technologies are ongoing, the remaining section reconsiders the specific kinds of tactility and 'immersion' recently industrially mobilised.

In the same way that 3-D cinema is concerned with the engineering of a 'realistic' sense of depth, so too is 'haptics' underpinned by the engineering of "realistic feelings of touch" (Paterson 2007: 12). Interestingly, however, there is a shift occurring in both these sectors. In addition to a focus upon the tactile (albeit in different guises) we are witnessing increasing industrial engagement with the wider multi-sensory palette, or what Thrift (2011: 5) labels the "mass produc[tion of] phenomenological encounter". Through unpacking recent technological iterations and advancements in both areas, namely '4-D' and '5-D' cinema and 'augmented reality’ respectively, I aim to illustrate this increasingly sophisticated sensory engagement and to highlight some questions it puts forth to media geographers.

For those unfamiliar, '4-D' and '5-D' cinema are industry terms that refer to the addition of physical effects to (3-D) cinema. Akin to 3-D cinema, such 'innovations' can too be understood as iterative technologies and of course have historical lineages. Consider, for example, the presence of seats with a conductive capacity, supplying a mild electric shock to film consumers in wired cinema seats in the 1959 title 'The Tingler' (Heffernan 2002: 56). I seek not to obfuscate the refinement or redesign of such physical cinematic additions, but rather to focus upon the recent 4-D and 5-D cinematic innovations specifically as they illustrate the increasingly sophisticated sensory engagement of this wider technological shift.

A notable global 'motion effects theatre' company specialising in 4-D and 5-D experiences advertise them as such:

"Live the experience: 3D you see, 4D you feel, and 5D you move... With sight, sound, motion and touch, you'll experience a sensory sensation like none other. Be a part of the film... Feel the motion on the screen and the effects around you. With special effects including air blasters, leg ticklers, seat transducers and pops, water blasts, rain, fog, winds and even strobing - enter the 5th dimension with Media Nation's X4D... perfectly programmed to simulate the exact movement you see on the screen" (Media Nation 2014: n.p.)

Akin to the gyrating 'motion seats' advertised by D-Box in the opening of this section, with the addition of such physical effects we witness an industrial shift from not only considering the (perceptually mimetic) construction of a 'realistic' 3-D object or view, to also a consideration of how 'realistic' an experience 'feels'. In that which 'Media Nation' refer to as "sensory entertainment" lies an appeal to our entire sensory palette. Rather than a focus on a more 'tactile' or depth-rich image, the addition of physical stimuli seeks to engage a human sensorium in concert. Rather than to evoke a texture or reverberation through cinematography alone, we are physically stimulated to 'feel' the cinematic encounter. As a visitor to North Korea's 'Runga 4-D simulation centre' reports "the glasses, 3D scenes, music effect, and rhythmic facilities enable the viewer to feel a vivid reality" (Guardian 2014: n.p.).

Akin to such cinematic advancements, recent developments in the area of 'haptics', explored here through the example of 'augmented reality' technologies, have similarly sought to engage with a wider sensory palette in order to further 'immerse' users in the media environment. Augmented reality refers to superimposing or mixing of three-dimensional virtual and synthetic images with the 'real world' (Brodlie and El-Khalili 2002: 35; Hedley et al 2002: 119). Augmented reality can be seen as an extension of virtual reality, in which a user interacts with a wholly synthetic environment. Augmented reality is currently enjoying the media limelight courtesy of a particular device, Google's notorious 'Glass'. The augmented reality sphere (often in combination with 'wearable' technology) is also frequently referred to as the "next generation of soon-to-be ubiquitous technology" (CNET 2014: n.p.) across technology media, blogs and forums more widely. 'Glass' will be revisited and expounded upon shortly. 
Geographical scholarship has recently begun to consider augmented reality as an increasingly significant player in the wider media landscape. Notable explorations include Graham et al's (2012: 465) discussion of the rapid growth in "virtual representations of place" through the case of digitally augmented maps. Graham et al (2012: 465) foreground questions around their role "in the production and experiences of places as augmented realities". Similarly, Graham and Zook (2013: 77) build upon this exploration of "augmentations and mediations of place" through an analysis of "online content indexed within Google Maps" and the "uneven linguistic geographies" that influence how "place is enacted and brought into being". Whilst such scholarship is invaluable in bringing to the fore questions around the co-constitutive character of such augmentations, it deals predominantly with mapping augmentations and the uneven politics of inclusion and exclusion. I similarly wish to acknowledge the rise and significance of the technology but to consider it through a different lens. Graham et al (2012: 466) do reflect briefly upon the "dynamic, arguably more immersive and haptic reading performances (relative to analogue augmentations) via infinitely malleable, touchscreen interfaces", and it is this point this paper wishes to centralise. It wishes to build upon this literature by considering augmented reality as illustrative of a wider media technology shift towards increasingly sophisticated multi-sensory engagement.

Google's 'Glass' can be described as glasses with a small camera and screen in the top corner of the right side lens-frame. Functioning predominantly through voice, gesture controls and a small touchpad on its side, 'Glass' acts like a small smartphone, harnessing the ability to take pictures, record data, upload to social media, browse the web, and send messages (Google Glass 2014a: n.p.). 'Glass' thus blends virtual content such as navigation, communications and simple searches into a real world context (Engadget 2013: n.p.). Due to its utilisation of prescription glasses architecture, the camera positioning means 'Glass' operates at eye-level, providing a 'natural' or sensorially-mimicking first-person viewpoint. The technological strides exhibited by 'Glass' in the area of gesture control reflect this relentless drive for 'natural' experience and the (re)creation (and enhancement) of sensory functionalities. Such efforts to mirror or mimic sensory reflexes or technologically (re)create forms of muscle memory illustrate precisely this wider sensory engagement, mimicry and the goal of technological integration. As Google's vice president and 'Chief Internet Evangelist' Vinton Cerf remarked, such devices strive to be our "sensory environment in context”" (Cerf 2013).

'Glass' has periodically gone on sale in 'beta' format to those consumers it calls 'Explorers' who wish to buy, test and feedback on the technology with a UK price-tag of $£ 1000$ prior to full public release (Google Glass 2014b: n.p.). 'Glass' sales have since been halted (January 2015), though Google reportedly remain "committed to the idea of smart glasses", and continue to develop them in a new division (BBC News 2015; Guardian 2015). Despite these staggered and stilted releases to date, already we are witnessing the development of augmented reality applications for 'Glass'. 'Layar', for example, is an application allowing users to compare real-world objects before them with a database of related virtual information via the verbal command: "Ok Glass, scan this" (Wired 2014: n.p.). Uses include watching a movie trailer prompted by the scanning of a movie poster or looking at real-estate information when in front of a specific property (Wired 2014: n.p.). 'Glass' is also by no means the only augmented reality device to receive considerable attention in technology circles. Products such as the forthcoming 'Space Glasses' from 'Meta' allow users “to interact with virtual objects [3-D holograms] in the real world", by scanning "your environment and tell[ing] the computer where to place the 3-D graphics relative to the user” (CNN 2013: n.p.). The user's body is thus fully 'immersed' and both virtual and actual activities fully integrated into their experience. As Meta (2014: n.p.) itself advertises: "the strongest tools have never been those that divide us from the world we live in".

This section has sought to bring into conversation recent cinematic and 'haptics' developments in order to illustrate a wider media technological engineering and experiential shift beyond the 'tactile' and towards the 'multi-sensory'. Encompassing various forms of 'mimetic engineering', these developments are (packaged as) increasingly perceptually-convincing, 'natural' and 'immersive'. Looking forward, such analyses may be extended with reference to the development of a dialogue between explorations of 'mimetic engineering' and literatures acknowledging the perceptually co-constitutive character of technology. The 'technological unconscious', proposing that the sensorium is adaptive, coevolves and is constantly reinvented through interaction with technology (Clough 2000; Kinsley 2010; Thrift 2004, 2005, 2007, 2011), may be one such avenue. The 'technological unconscious' appreciates the constitutive role of technology (or media technology device) as that more than mediation. Here, we may consider the example of the 'iPad' that is at once described as changing "the bodily expectation of the interface" and a technology that "millions... [will] be instantly familiar with" (Kinsley 2010: 2783). As has been illustrated through a discussion of 3-D cinema and haptic media technology, within these increasingly commercially lucrative fields the operational devices and technologies themselves (glasses, screens, seats, controllers) play a key role in both the emulation of the sensorial encounter and in the consumption experience itself. Such an exploration would aid in attending to both 
the concern that focusing only on media "communication content...truncates communication" (Adams 2013: 266), and acknowledge the importance of the changing function and role of technological devices. Here, further dialogue with literatures such as 'haptics' and 'user-interface design' may aid in unpacking complex questions around media physicality, illusion and interaction. Such questions could be more fully worked through in the context of such media where, at times, "action is tantalisingly close but never fully touchable" (Ross 2013: 406).

\section{Conclusion}

This paper aimed to provide a sustained consideration of the previously under-examined, yet commercially and popularly notable, media format of 3-D cinema. It first considered the 3-D cinema as an affective storytelling medium, both in terms of its depth-rich appeals and the industrial marketing rhetoric surrounding it. In so doing, it found the motif of 'immersion' as both entrenched and central in the medium's wider identity. The medium's central component of 'immersion' was then unpacked and an emergent coupling between 'immersion' and a particular form of perceptually-mimicking engineering (which could be termed 'mimetic engineering') explored. Finally, geographic literatures exploring the technological realm of 'haptics' and technologies of touch were drawn upon to both explore and complicate the association of 3-D cinema with 'tactility'. Here the importance of considering the device itself as a key component of media consumption was noted. Recent advancements in both fields (cinema and 'haptics') were then drawn upon in order to propose a shift to the engineering of an increasingly sophisticated engagement with a wider sensory palette, relentlessly packaged as ever more 'immersive' consumer experience.

Whilst such advancements in 3-D cinema and related media technologies more widely may not yet have reached the fictitious heights envisioned by Aldous Huxley in the paper's opening passage, this sci-fi fantasy, underpinned by the same emulation of 'realistic' experience presented as an 'immersive' media quality, is certainly no longer the stuff of fantasy but the subject of fervent industrial research and development. Strides are being made in producing and cultivating ever more perceptually-convincing media encounters. Such encounters increasingly engage with a wider sensory palette, reflecting sophisticated advances in 'mimetic engineering' across the wider media technological landscape. Given the commercial success and lucrative character of such advancements it is unsurprising that forthcoming technologies are following and extending such developmental trajectories.

In addition to 3-D cinema's advancements in "heightened sensory experience" (Klinger 2013: 424), a number of popular media devices are similarly boasting increasingly complex sensory considerations. From 'Meta's' aforementioned 'Space Glasses' to MIT's 'sensory fiction', which is described as "wearable and immersive" reading utilising "extra-lexical components like sound, temperature control, vibration, and ambient lighting to tell its stories" (The Atlantic 2014: n.p.), we are seeing an increasing sensory engagement and commodification across the wider technological media landscape. In the face of the rise of such technologies centred around multi-sensory verisimilitude, questions around the changing character of media 'immersion' and its underpinning by increasingly complex forms of 'mimetic engineering' are thus of increasing import.

Acknowledgements: With special thanks to Dr John Finn and Dr Joseph Palis for their organisation of the Geographies of Media session at the AAG (2013), and their advice and encouragement with the paper. Thanks to my supervisors, Dr Sean Carter and Dr Pepe Romanillos, for their continued support and encouragement, and also to the anonymous referees for their valuable insights. All mistakes are my own. 


\section{References}

Adams, P.C. (2013) Media. In (eds) Dodds, K., Kuus, M., Sharp, J. (2013) The Ashgate research companion to critical geopolitics (pp.263-280). Farnham, U.K: Ashgate.

AIS (2013) American Industrial Systems, Inc. What's new in Multi Touch? White Paper. http://www.aispro.com/news/multi-touch-technology-white-paper . Accessed 2 January 2014.

Aitken, S.C., Dixon, D.P. (2006) Imagining Geographies of Film. Erdkunde, 60 (4), 326 - 336.

Ash, J. (2009) Emerging spatialities of the screen: video-games and the reconfiguration of spatial awareness. Environment and Planning A, 41 (9), 2105-2124.

Ash, J. (2010a) Teleplastic technologies: charting practices of orientation and navigation in videogaming. Transactions of the Institute of British Geographers, 35 (3), 414-430.

Ash, J. (2010b) Architectures of affect: anticipating and manipulating the event in practices of videogame design and testing. Environment and Planning D: Society and Space, 28 (4), 653-671.

Ash, J. (2012) Technology, technicity, and emerging practices of temporal sensitivity in videogames. Environment and Planning A, 44 (1), 187-203.

Ash, J., Gallacher, L.A. (2011) Cultural Geography and Videogames. Geography compass, 5/6, 351-368.

Ash, J.N., Romanillos, J.L., Trigg, M. (2009) Videogames, visuality and screens: reconstructing the Amazon in physical geographical knowledge. Area, (41) 4, 464-474.

Barnett, C. (2008) Political affects in public space: Normative blind-spots in non-representational ontologies. Transactions of the Institute of British Geographers, 33 (2), 186-200.

BBC News (2013) Gravity powers to number one spot at UK box office. http://www.bbc.co.uk/news/entertainment-arts-24924886 . Accessed: 3 January 2014.

BBC News (2015) Google Glass sales halted but firm says kit is not dead. http://www.bbc.co.uk/news/technology-30831128 Accessed: 15 January 2015.

British Film Institute (2013) British Film Institute: Statistical Yearbook 2013.

http://www.bfi.org.uk/sites/bfi.org.uk/files/downloads/bfi-statistical-yearbook-2013.pdf . Accessed 10 January 2014.

Brodlie, K., El-Khalili, N. (2002) Web-based Virtual Environments. In (eds) Fisher, P., Unwin, D. (2002) Virtual Reality in Geography (pp.35-46). London, U.K: Taylor \& Francis.

Bruno, G. (2002) Atlas of Emotion: Journeys in Art, Architecture, and film. New York: Verso.

Carter, S., Dodds, K. (2011) Hollywood and the 'war on terror': genre-geopolitics and 'Jacksonianism' in The Kingdom. Environment and Planning D: Society and Space, 29 (1), 98 - 113.

Carter, S., McCormack, D. (2006) Film, Geopolitics and the Affective Logics of Intervention. Political Geography, 25 (2), 228 - 243.

Carter, S., McCormack, D. (2010) Affectivity and Geopolitical Images in (eds) Dodds, K., Hughes, R., MacDonald, F. (2010) Observant States: geopolitics and visual culture. U.K: I.B Tauris \& Co. Ltd

Cerf, V. (2013) Campus Party Technology Festival Keynote Talk. O2 Arena, London, 2-7 September 2013.

Clough, P. T. (2000) Autoaffection: unconscious thought in the age of teletechnology. Minneapolis, U.S: University of Minnesota Press.

CNET (2014) Wearables with augmented reality are mind-blowing -- and an ethical nightmare.

http://www.cnet.com/uk/news/wearables-with-augmented-reality-are-mind-blowing-and-an-ethical-nightmare/ Accessed: 2 June 2014. 
CNN (2013) Glasses to make you a real-life Tony Stark.

http://edition.cnn.com/2013/10/31/tech/innovation/meta-augmented-reality-glasses/ Accessed: 2 June 2014.

COW (2012) High Frame Rate Cinema. http://library.creativecow.net/kaufman_debra/High-Frame-RateCinema/1 Accessed: 1 June 2014.

Crang, M. (2002) Rethinking the Observer: Film, Mobility, and the Construction of the subject. In (eds) Cresswell, T., Dixon, D. (2002) Engaging Film: Geographies of Mobility and Identity. Oxford, U.K: Rowman \& Littlefield Publishers, Inc.

Crary, J. (1992) Techniques of the observer: On vision and modernity in the nineteenth century. Massachusetts, U.S: MIT Press.

Currys (2013) Currys PC Word Discover Everything Apple: Tablet Advertisement.

http://www.tvadmusic.co.uk/2013/12/currys-pc-world-discover-everything-apple/ Accessed 15 December 2013.

Currys (2014) LG 55EA980W Smart 3D 55" Curved OLED TV. Advertisement.

http://www.currys.co.uk/gbuk/tv-dvd-blu-ray/televisions/large-screen-tvs-32-and-over/lg-55ea980w-smart-3d55-curved-oled-tv-21761480-pdt.html Accessed: 1 June 2014.

D-Box (2014) Products. MFX-132 Lounger. http://www.d-box.com/en/consumer/theater_products Accessed: 1 June 2014.

Digital Trends (2013) How to trade paper for pixels - and keep writing by hand. Resource Document. http://www.digitaltrends.com/mobile/best-digital-pens-writing-apps-and-stylus-tablets/ . Accessed 3 January 2014.

Dittmer, J. (2005) Captain America's Empire: Reflections on Identity, Popular Culture, and Post-9/11 Geopolitics. Annals of the Association of American Geographers, 95 (3), 626-643.

Dittmer, J. (2007) The Tyranny of the Serial: Popular Geopolitics, the Nation, and Comic Book Discourse. Antipode, 39 (2), 247-268.

Dittmer, J. (2010) Popular culture, Geopolitics and Identity. Maryland, U.S: Rowman \& Littlefield Publishers, Inc.

Dittmer, J. (2011) American exceptionalism, visual effects, and the post-9/11 cinematic superhero boom. Environment and Planning D: Society and Space, 29 (1), 114-130.

Dittmer, J., Dodds, K. (2013) The Geopolitical Audience: Watching Quantum of Solace (2008) in London. Popular Communication: The International Journal of Media and Culture, 11 (1), 76-91.

Dixon, D., Grimes, J. (2004) Capitalism, masculinity and whiteness in the dialectical landscape: The case of Tarzan and the Tycoon. GeoJournal, 59, 265-275.

Dodds, K. (1998) Enframing Bosnia, the geopolitical iconography of Steve Bell. In Dalby, S., Toal, G.(eds) (1998) Rethinking geopolitics (pp.170-197). London, UK: Routledge.

Dodds, K. (2010a) Popular Geopolitics and Cartoons: Representing power relations, repetition and resistance. Critical African Studies, 2 (4), 113-131.

Dodds, K. (2010b) Jason Bourne: Gender, Geopolitics, and Contemporary Representations of National Security. Journal of Popular Film and Television, 38 (1), 21-33.

DVICE (2013) Step aside IMAX, screen X movies use three giant screens. http://www.dvice.com/2013-1017/step-aside-imax-screenx-movies-use-three-giant-screens Accessed: 1 June 2014.

Engadget (2013) Google Glass Review. https://www.youtube.com/watch?v=j81ScHO2mM0 Accessed: 20 May 2014.

Elsaesser, T. (2013) The "Return" of 3-D: On Some of the Logics and Genealogies of the Image in the TwentyFirst Century. Critical Inquiry, 39 (2), 217-246. 
Falah, G.W., Flint, C., Mamadouh,V. (2006) Just War and Extraterritoriality: The Popular Geopolitics of the United States' War on Iraq as Reflected in Newspapers of the Arab World. Annals of the Association of American Geographers, 96 (1), 142-164.

Freeland, C. (2012) On being stereoblind in an era of 3D movies. Essays in Philosophy, 13 (2), 550-576.

Gizmodo (2012) The Hobbit: An Unexpected Masterclass in Why 48 FPS Fails. http://gizmodo.com/5969817/the-hobbit-an-unexpected-masterclass-in-why-48-fps-fails . Accessed 4 January 2014.

Glynn, K., Cupples, J. (2014) Negotiating and queering US hegemony in TV drama: popular geopolitics and cultural studies. Gender, Place and Culture: A Journal of Feminist Geography. doi: 10.1080/0966369X.2013.855711

Google Glass (2014a) Google Glass: What it does. http://www.google.co.uk/glass/start/what-it-does/ Accessed: 1 June 2014.

Google Glass (2014b) Google Glass Explorer Edition (Shale). https://play.google.com/store/devices/details?id=glass_shale Accessed: 10 June 2014.

Graham, M., Zook, M., Boulton, A. (2012) Augmented reality in urban places: contested content and the duplicity of code. Transactions of the Institute of British Geographers, 38, 464-479.

Graham, M., Zook, M. (2013) Augmented Realities and uneven geographies: exploring the geolinguistic contours of the web. Environment and Planning A, 45, 77-99.

Guardian (2010) The Guardian News: Twentieth Century Fox's 3D gamble pays off with billion dollar blockbuster. http://www.theguardian.com/film/2010/jan/04/avatar-3d-film-twentieth-century-fox . Accessed: 5 January 2014.

Guardian (2014) Thousands of North Koreans enjoy 'rhythmic' 4D cinema. http://www.theguardian.com/world/2014/may/21/north-korea-4d-cinema-rhythmic Accessed: 1 June 2014.

Guardian (2015) Google Glass ceases production 'in present form'. http://www.theguardian.com/technology/2015/jan/15/google-glass-ceases-production-for-now . Accessed: 16 January 2015.

Gurevitch, L. (2012) The Birth of a Stereoscopic Nation: Hollywood, Digital Empire and the Cybernetic Attraction. Animation. 7, 239-258, doi: 10.1177/1746847712456255

Hawkins, R.C. (1953) Perspective on “3-D”. The Quarterly of Film Radio and Television, 7 (4), 325-334.

Hedley, N.R., Billinghurst, M., Postner, L., May, R., Kazo, H. (2002) Explorations in the Use of Augmented Reality for Geographic Visualization. Presence, 11, (2),119-133.

Heffernan, K. (2002) The Hypnosis Horror Films of the 1950s: Genre Texts and Industrial Context. Journal of film and video, 54 (2/3), 56-70.

Holland, E. (2012) To Think and Imagine and See Differently: Popular Geopolitics, Graphic Narrative, and Joe Sacco's: Chechen War, Chechen Women. Geopolitics, 17 (1), 105-129.

Howard, I.P., Rogers, B.J. (1995) Binocular Vision and Stereopsis: Oxford Psychology Series No. 29. New York: Oxford University Press.

Hughes, R. (2010) Gameworld Geopolitics and the Genre of the Quest. In Dodds, K., Hughes, R., MacDonald, F. (eds) (2010) Observant States: geopolitics and visual culture (pp.123-142). UK: I.B Tauris \& Co. Ltd.

Hughes, R. (2013) Geopolitics and Visual Culture. In (eds) Dodds, K., Kuus, M., Sharp, J. (2013) The Ashgate research companion to critical geopolitics (pp.69-88). Farnham, U.K: Ashgate.

IMDB (2013a) Reviews and Ratings for 'Gravity'. http://www.imdb.com/title/tt1454468/reviews?ref_=tt_urv Accessed: 15 May 2014. 
IMDB (2013b) Reviews and Ratings for 'Gravity'. http://www.imdb.com/title/tt1454468/reviews?start=30 Accessed: 12 June 2014.

Independent (2013) The Independent News: Widescreen, immersive and no funny glasses: Is this the future of 3D cinema? http://www.independent.co.uk/life-style/gadgets-and-tech/features/widescreen-immersive-and-nofunny-glasses-is-this-the-future-of-3d-cinema-8879849.html . Accessed: 14 October 2013.

Johnson, E. R. (2010) Reinventing biological life, reinventing 'the human'. Ephemera, 10 (2), 177-193.

Johnson, E.R. (2011) Reanimating Bios: Biomimetic Science and Empire. PhD Thesis. http://conservancy.umn.edu/bitstream/117375/1/Johnson_umn_0130E_12236.pdf Accessed: 6th June 2014.

Kinsley, S. (2010) Representing 'things to come': feeling the visions of future technologies. Environment and Planning A, 42 (11), 2771-2790.

Kitchin, R., Dodge, M. (2011) Code/space: Software and Everyday Life. U.S: Massachusetts Institute of Technology.

Klinger, B. (2013) Three-dimensional cinema: The New Normal. Convergence: The new International Journal of Research into New Media Technologies, 19 (4), 423-431.

Kovac, M. (2014) The Bioinspiration Design Paradigm: A Perspective for Soft Robotics. Soft Robotics, 1 (1), 28-37.

Lipton, L. (2010) Chapter 5: Stereoscopic 3-D. In Okun, J.A., Zwerma, S. (eds) (2010) The VES Handbook of Visual Effects (pp. e5-1 - e-20). Oxon, U.K: Elsevier.

Loew, K. (2013) Tangible Specters: 3-D Cinema in the 1910s. Film Criticism, 37/38 (3/1), 87-116.

Lukinbeal, C. (200). The Map that Precedes the Territory: An Introduction to Essays in Cinematic Geography. GeoJournal, 59 (4), 247-251.

Lukinbeal, C., Zimmermann, S. (2006) Film Geography: A new subfield. Erdkunde, 60 (4), 315-325.

Lukinbeal, C., Zimmermann, S. (2008) The Cinematic World. In Lukinbeal, C., Zimmermann, S. (eds) The Geography of Cinema - a Cinematic World (pp. 14-23). Stuttgart: Franz Steiner Verlag.

Marks, L. (2000) The Skin of the Film: intercultural cinema, embodiment and the senses. US: Duke University Press.

Media Nation (2014) X4D. Advertisement. http://www.mediamation.com/videos/MM_X4D.html Accessed: 1 June 2014.

Mendiburu, B. (2012) 3D TV and 3D Cinema: Tools and Processes for Creative Stereoscopy. Oxford, U.K: Elsevier Inc.

Meta (2014) Meta. Space Glasses. Advertisement. https://www.spaceglasses.com/ Accessed: 4 June 2014.

MIT Technology Review (2010) Is 3-D bad for you? http://www.technologyreview.com/news/418319/is-3dbad-for-you/ . Accessed: 3 January 2014.

Motion Picture Association of America (2013) 2012 Theatrical Statistics Summary.

http://www.mpaa.org/resources/3037b7a4-58a2-4109-8012-58fca3abdf1b.pdf . Accessed: 21 November 2013.

Odeon (2014) 3-D film advertisement. http://www.odeon.co.uk/3d/ Accessed: 1 June 2014.

Ofcom (2013) Communications Market Report 2013.

http://stakeholders.ofcom.org.uk/binaries/research/cmr/cmr13/2013 UK_CMR.pdf. Accessed: 2 January 2014.

Paterson, M. (2006) Feel the presence: technologies of touch and distance. Environment and Planning D:

Society and Space, 24 (5), $691-708$.

Paterson, M. (2007) The Senses Of Touch: Haptics, Affects and Technologies. Oxford, U.K: Berg. 
PC Mag (2013) Definition: Multi touch. http://www.pcmag.com/encyclopedia/term/59067/multitouch. Accessed 3 January 2014.

PC World (2014) Tablet advertisement: Microsoft Surface. http://www.pcworld.co.uk/gbuk/laptops-

netbooks/ipad-tablets-and-ereaders/tablets/microsoft-surface-2-10-6-tablet-32-gb-21765543-pdt.html . Accessed 10 January 2014.

Pew Research Centre (2013a) Smartphone Ownership 2013 Update.

http://www.pewinternet.org/ /media/Files/Reports/2013/PIP_Smartphone adoption_2013.pdf . Accessed 20

December 2013.

Pew Research Centre (2013b) Tablet Ownership 2013.

http://pewinternet.org/ /media//Files/Reports/2013/PIP_Tablet\%20ownership\%202013.pdf. Accessed: 20

December 2013.

Pile, S. (2011) Chapter 25: Intensities of feeling: Cloverfield, the uncanny, and the always near collapse of the city. In Bridge, G., Watson, S. (eds) (2011) The New Blackwell Companion to the City (pp.288 - 304). Oxford, U.K: John Wiley \& Sons Ltd.

Pinkerton, A. (2013) Journalists. In (eds) Dodds, K., Kuus, M., Sharp, J. (2013) The Ashgate research companion to critical geopolitics (pp.439-460). Farnham, U.K: Ashgate.

Pinkerton, A., Dodds, K. (2009) Radio geopolitics: broadcasting, listening and the struggle for acoustic spaces. Progress in Human Geography, 33 (1), 10-27.

Playstation (2014) Playstation 4 Accesories. http://uk.playstation.com/ps4/features/dualshock4/ . Accessed 4 January 2014.

PopSci (2013) Wingnut Films and Park Road Post Production HFR 3-D.

http://www.popsci.com/bown/2013/product/wingnut-films-and-park-road-post-production-hfr-3$\underline{\mathrm{d} ? \mathrm{src}=\mathrm{SOC} \& \mathrm{dom}=\mathrm{fb}}$. Accessed 20 December 2013.

Power, M. (2007) Digitised virtuosity: video war games and post 9/11 cyberdeterrence. Security Dialogue, 38 (2), 271-288.

Power, M., Crampton, J. (2005) Reel Geopolitics: Cinemato-graphing Political Space. Geopolitics, 10 (2), 193 203. doi: $10.1080 / 14650040590946494$

Prince, S. (2012) Digital Visual Effects in Cinema: The Seduction of Reality. U.S: Rutgers University Press.

Reel Cinema (2014) Reel Cinema: Digital. Advertisement. http://www.reelcinemas.co.uk/digital.html . Accessed 10 January 2014.

Reeve, S., Flock, J. (2010) Basic Principles of Stereoscopic 3-D. BSKYB.

http://www.sky.com/shop/export/sites/www.sky.com/shop/_PDF/3D/Basic_Principles_of_Stereoscopic_3D_v 1.pdf . Accessed 1 January 2014.

Ross, M. (2012) The 3-D aesthetic: Avatar and hyperhaptic visuality. Screen, 53 (4), 381 - 397, doi: 10.1093/screen/hjs035

Ross, M. (2013) Stereoscopic visuality: Where is the screen, where is the film? Convergence: The International Journal of Research into New Media Technologies, 19 (4), 406-414.

Samsung (2014) Tablet Features: Galaxy Note 10.1 WiFi. Advertisement. http://www.samsung.com/uk/consumer/mobile-devices/tablets/tablets/GT-N8010EAABTU-features . Accessed 4 January 2014.

Shapiro, M.J. (2009) Cinematic Geopolitics. UK: Taylor \& Francis.

Sharp, J.P. (1998) Chapter 7: Reel Geographies Of The New World Order: Patriotism, Masculinity and Geopolitics in Post-Cold War American Movies. In Dalby, S., Ó Tuathail, G. (eds) (1998) Rethinking Geopolitics (pp.152-167). UK: Routledge. 
Sharp, J.P. (2000) Condensing the Cold War: Reader's Digest and American Identity. U.S: University of Minnesota Press.

Shaw, I.G.R. (2010) Playing war. Social \& Cultural Geography, 11 (8), 789-803.

Shaw, I.G.R., Sharp, J.P. (2013). Playing with the Future: Social Irrealism and the Politics of Aesthetics. Social and Cultural Geography, 14 (3), 341-359.

Shaw, I.G.R., Warf, B. (2009) Worlds of affect: virtual geographies of video games. Environment and Planning: $A, 41$ (6), 1332-1343.

Sobchack, V. (2004) Carnal Thoughts: Embodiment and Moving Image Culture. Los Angeles: University of California Press.

Stahl, R. (2006) Have you played the war on terror? Critical Studies in Media Communication, 23 (2), 112-130.

Tech Radar (2012) Do we need higher frame rates? http://www.techradar.com/news/home-cinema/highdefinition/do-we-need-higher-frame-rates-1072784 Accessed: 1 June 2014.

Tested (2014) 48fps and beyond: How High Frame Rate Films Affect Perception.

http://www.tested.com/art/movies/452387-48-fps-and-beyond-how-high-frame-rates-affect-perception/.

Accessed: 16 January 2014.

The Atlantic (2014) The Book You Read Feel. http://www.theatlantic.com/technology/archive/2014/01/thebook-you-strike-read-strike-feel/283424/. Accessed: 29 January 2014.

The Oxford English Dictionary (2014) Definition of 'immersion'.

http://www.oxforddictionaries.com/definition/english/immersion?q=immersion Accessed: 12 June 2014.

The Verge (2013) 270- degree Screen X technology shows ultra-wide movies on three walls.

http://www.theverge.com/2013/10/18/4850870/screenx-shows-movies-270-degrees-on-three-walls Accessed: 1 June 2014.

Thrift, N. (2004) Remembering the technological unconscious by foregrounding knowledges of position.

Environment and Planning D.: Society and Space, 22 (1), 175-190.

Thrift, N. (2005) From born to made: technology, biology and space. Transactions of the Institute of British Geographers, 30 (4), 463-476.

Thrift, N. (2007) Non-representational Theory: space, politics, affect. London, U.K: Routledge.

Thrift, N. (2011) Lifeworld Inc - and what to do about it. Environment and Planning D: Society and Space, 29 (1), 5-26.

Walters, B. (2009) The Great Leap Forward. Sight \& Sound, 19 (3), 38-43.

Wired (2014) Augmented Reality: Layar on Google Glass. http://www.wired.com/2014/03/augmented-realitylayar-google-glass/ Accessed: 15 May 2014.

Yang, S., Schlieski, T., Selmins, B., Cooper, S.C., Doherty, R.A., Corrivea, P.J., Sheedy, J.E. (2012)

Stereoscopic Viewing and Reported Perceived Immersion and Symptoms. Optometry and Vision Science, 89 (7), 1068-1080. doi: 10.1097/OPX.0b013e31825da430

Youtube (2013) Playstation Station Channel: Playstation Dual Shock controller 4. http://www.youtube.com/watch?v=wPeBWguyGjM . Accessed 25 April 2013.

Zone, R. (2007) Stereoscopic Cinema and the Origins of 3-D Film, 1838-1952. Kentucky, U.S: The University Press of Kentucky. 


\section{Filmography}

Cameron J (Dir.), 2009 Avatar (Twentieth Century Fox)

Cuarón, A. (Dir.), 2013 Gravity (Warner Bros)

Jackson, P. (Dir.) 2012 The Hobbit: An Unexpected Journey (New Line Cinema)

Jackson, P. (Dir.) 2013 The Hobbit: The Desolation of Smaug (New Line Cinema) 